\title{
IMPROVING PROPERTY AND CASUALTY INSURANCE COVERAGE
}

\author{
J. Edward Hedges*
}

Stated in positive terms, the fundamental raison d'être of insurance is to pay losses suffered by individuals, ${ }^{1}$ provided, of course, the risk was previously specifically assumed by contract and a proper premium paid for the protection afforded. Insurance is appropriately applied only to those hazards of loss which, in particular cases, would have disastrous effects if borne by the individual directly. Through the mechanism of insurance the burden of such losses may be reduced almost to insignificance by spreading the cost over all, or a substantial number, of those exposed to similar risks.

In times past it may have seemed that companies existed for the prime purpose of collecting premiums, and, when losses occurred, of seeking all means at their disposal to avoid payment. The "fine print" provisions hidden obscurely on the inside pages of policy forms once used are frequently cited as evidence of such a philosophy of operation. Be that as it may, as the institution of insurance has matured, its fundamental purpose has emerged more and more clearly.

Today it seems reasonable to say that a substantial portion of the energies of the entire institution are directed toward the conduct of business in such a way as to make sure that major hazards of individuals are insured and when losses occur that they are paid promptly and in full. ${ }^{2}$ By what steps has this stage been reached; what problems have been faced and overcome; what problems yet remain to be solved; and what are the prospects for their solution? In the discussion that follows, attention will be directed toward these questions as they apply to the property and casualty insurance ${ }^{3}$ field.

- A.B. 1928, Baker University; M.B.A. 1932, University of Kansas; Ph.D. 1936, Johns Hopkins University; C.L.U. 1938; C.P.C.U. 1947. Assistant Professor of Economics, Emory University, 19351940. Assistant Professor 1940, Associate Professor 1942, Professor of Insurance 1946, Indiana University. Visiting Professor of Insurance, University of California at Los Angeles, spring I950. Secretary-Treasurer, American Association of University Teachers of Insurance. Author, Practical Fire and Casualty Insurance (1943, 1946, 1948); co-author (with Lem Paul Hensler), Compensation of Life Insurance AGENTS (1942). Contributor to Economic and Insurance periodicals.

"The term "individuals" is used here in a broad sense, to include not only natural persons but business entities such as partnerships and corporations as well.

${ }^{2}$ In fairness, it must be pointed out that present day policies, even the most comprehensive, do contain restrictions. Most such restrictions exist, not only for the protection of the company and its resources, but equally for the protection of the public whose costs might otherwise become both excessive and inequitable. It has been well stated that an important purpose of restrictions is to protect the rate at which the coverage is written. Those who require broader coverage may secure it by the payment of appropriate extra premiums, while those who do not require it-or want it-need not pay. Thus equity is preserved. This question will be explored further, below.

3 The present-day division of the insurance business into a number of branches and the titles applied to these branches are largely the result of historical accident. These traditional divisions have been perpetuated by their adoption in the insurance codes of the various states. Thus, it has become customary to divide insurance into life, fire and marine, casualty, and (usually) corporate bonding, the 


\section{Forces aNd Processes}

This paper is more concerned with the present status of insurance coverage as related to the public's insurance needs, than with those processes by which the present state has been attained. Nevertheless, it seems desirable to devote some attention to the forces which have operated in the past to produce the present situation as to coverage, as well as to the forces which may be expected to operate in the future, with some attention to the ways in which they work.

The process with which we are concerned may be described briefly somewhat as follows. First, it is the task of the insurance carrier, if it is to perform its function properly and to enjoy the prospect of financial success, to determine accurately the needs of the public and to make available the appropriate coverage at a rate that is adequate and equitable. The "producer" or agent, with the guidance or assistance of the carrier's field forces, then must attempt to appraise the needs of his client and to apply the best coverage available. The acid test of the effectiveness of the whole mechanism lies in the extent to which the losses of the client may properly be paid under the coverage he holds. The carriers themselves, through participation of their field forces in the adjustment process, become aware of defects in policies and forms as well as shortcomings in the adaptation of available coverage to the needs of the public. If this is not sufficient, the agent quickly conveys to the company any public dissatisfaction with the forms of coverage available.

But outside the insurance mechanism itself, the tremendous importance to the public of the way in which the insurance business is conducted has led to a gradually expanding intervention and supervision by the government-first by the states independently, and now under certain Congressional directives. ${ }^{4}$ Thus, adjustments

latter sometimes being included in the "casualty" category. The author has long urged the adoption of a more logical division into personal, having to do with hazards to persons, such as death, injury and illness; and property, including those forms dealing with hazards to property. In the latter category would be included two main types of hazards: namely, hazards of direct loss or destruction of specific items of property (loss of a building by a fire, money by theft, etc.); and hazards of loss of any or all property owned or subsequently acquired, through legal liability for damage to the persons or property of others. In this paper the redundant phrase "property and casualty insurance" will be replaced by the more simple and logical one "property insurance"-which will include both direct loss and liability as indicated above. The customary terms will be used, of course, when reference to the traditional divisions is necessary.

The Regulation of Insurance Act, 59 STAT. 33 (1945), 59 U. S. C. §ror 1 et seq. (1940), following the case of United States v. South-Eastern Underwriters Association, 322 U. S. 533 (1944), in which insurance was declared to be interstate commerce and consequently within the regulatory power of Congress, makes certain declarations with respect to regulation of insurance by the states. It declares that continued regulation and taxation by the several states of the business of insurance is in the public interest, that silence on the part of Congress shall not be construed to impose any barrier to such regulation, and that no act of Congress shall be construed to supersede any state law for the regulation of insurance unless such act specifically relates to the business of insurance. The act then procecds to make the Sherman Act, the Clayton Act, and the Federal Trade Commission Act applicable to the business of insurance after Jan. $x, 7948$, "to the extent that such business is not regulated by State law," with the exception that the Sherman Act is to apply to "any agreement to boycott, coerce, or intimidate, or act of boycott, cocrcion or intimidation." 
have had necessarily to be made with a view to regulatory statutes and administrative rulings. Sometimes the effect has been to retard needed progress, perhaps more frequently to prevent ill-advised changes or action by individual companies or groups, dictated by the desire to meet competitive situations and not in the long run interests of either the business or the public.

This sketch of the forces operating to adjust insurance coverage to needs would be incomplete without mention of what has been called "self-regulation," carried out primarily by inter-company associations or bureaus. While important functions of these groups have included accumulation of statistics for rate-making purposes, research and dissemination of loss prevention information, and other matters outside the scope of present consideration, many of their activities have been pertinent to the subject under discussion. The drafting of recommended uniform policies and forms and of rules for their application in the writing of various coverages are examples. Thus, adjustments frequently have come, not by the companies acting alone, or even in negotiation with the regulatory authorities, but by cooperative action involving the state and the companies acting through their associations.

The discussion so far has attempted to indicate the forces making for improvement in property insurance coverage and to outline the legal and institutional framework within which the forces have operated. As suggested above, in some respects this legal and institutional framework has had the effect of retarding change. Once a particular policy, provision, or group of provisions has been interpreted by the courts, its effect becomes known with reasonable certainty and those on the company side become loath to make changes. It is true, of course, that once a change has been made, unexpected interpretations may necessitate further change, an additional reason why there has been some reluctance to make changes in wording, even in the face of manifest obsolescence. In addition, the problem of securing agreement by the companies working through their various bureaus has sometimes retarded improvement. In many cases the way has been led by the independent or "non-bureau" or by the "small-bureau" companies," the others following as the usefulness of innovations became apparent or as competition forced their adoption.

One final aspect of the institutional framework of the industry has had a serious effect in retarding-even preventing-innovation. This is the rigid limitation placed on the insuring powers of companies authorized to write particular lines by the insurance laws of the various states. Fire and marine companies were restricted to certain material damage lines (such as fire, windstorm, and the like) and consequential loss lines (business interruption, rent or rental value, and similar

\footnotetext{
-For many years bureaus formed by insurance companies, or to whose services the companies subscribed, have operated on a regional or national basis. Prior to the passage of the Regulation of Insurance Act and the revisions in burcau organization which followed, members were usually required to use the forms and to abide by the rules promulgated by the bureaus. Companies not wishing to do so cither operated independently or formed their own bureaus to perform the same functions. Companies belonging to no bureau were called non-bureau companies or independents. Bureaus other than those dominating each field were called "little-bureaus" or "small-bureaus."
} 
losses resulting from material damage falling within their jurisdiction). These companies were excluded from such lines as burglary and robbery, public liability, workmen's compensation, etc., these being the special province of companies authorized to write "casualty" insurance. The result was the typically American system known as "mono-line." In the general overhauling of insurance regulatory laws which has taken place in the past few years, there has occurred a reversal of the mono-line principle. A majority of the states have now granted more or less liberal "limited multiple-line underwriting powers." Under these powers, companies meeting the specified requirements may now break over the old barriers and extend their coverage to include hazards previously prohibited. (In no case, however, have life insurance companies been permitted to enter the property field nor property carriers been authorized to enter the life insurance field, except, as was previously the case, that casualty companies frequently include the hazard of death in policies covering accident or illness.) The authorization of multiple-line underwriting removes one of the serious hurdles previously faced in any attempt to improve property insurance coverage and make it truly complete.

\section{II}

The Position of the Public

From the standpoint of making its needs felt, adapting available coverage to existing needs, and commanding adequate service, the public falls into several groups.

The first of these includes those large commercial or industrial organizations whose operations frequently cross state lines and even reach nation-wide proportions. Concerns of this kind have insurance problems of such magnitude and of such a continuing character that a full-scale department manned by a corps of specialists may be justified. While such concerns may place business through local agents, overall aspects of planning and administration are under the direct control of the company's own staff. Experts, with the assistance of the company's legal staff, may even go so far as to draw up their own forms for covering particular hazards.

Companies of the same type, as well as smaller concerns, may rely on insurance brokers or brokerage firms to represent them in the purchase and administration of their insurance. In such cases, the brokerage firm may act in much the same way as an insurance department of the company, thus relieving the company of the necessity of establishing such a department. Some brokerage firms have nation-wide facilities through which a service of this kind is offered.

Other business concerns rely on local agents, usually representing a number of fire and marine and casualty companies, to provide them with insurance service. Such agents, with the cooperation of their carriers and agents in the other communities in which the client may operate, compete with the brokerage type of operation,

- In Great Britain, in contrast, there is no such artificial delimitation of insuring powers. MArQuis JAMES, BIOGRAPHY OF A Business I792-I942 333 (1942).

${ }^{7}$ Cahill's Actuarial Society Address, Eastern Underwriter, November 25, 1949, p. 36. 
offering service as well to individuals and concerns whose operations are intra-state or local. A special tool developed for local agency operation is the insurance survey, by means of which needs are carefully and completely listed, existing insurance noted, and adjustments or additional insurance recommended. This device offers a means of noting and filling gaps in coverage and of adapting various forms so as to insure existing risks most adequately and economically.

Many individuals, of course, have only limited personal needs for insurance coverage. Such cases may not warrant detailed surveys, their risks lending themselves to a few "package" type policies. The problem of improving coverage here is simply one of making sure that the "package" forms available are sufficiently "comprehensive" for the typical case, and yet do not cover hazards which too often are unneeded and which, by their inclusion, may increase the cost unduly.

For the large mass of the public the method described first above (that of privately employing experts or engaging brokers to buy and administer the insurance required) would not be possible or practicable as a means of improving coverage. In many cases even the survey technique as applied by agents or brokers would not provide an adequate solution when available forms of coverage do not properly fit the hazard, leave uninsured gaps, or provide more coverage (at higher cost) than the need warrants, although it is often an important and necessary step. Problems of this kind must be solved for the public at large by improvements in the coverages offered.

While all of the needs and opportunities for improving property insurance coverage suggested above will be kept in mind in the discussion that follows, primary attention will be devoted to improvement in forms so as to make them more adequate. Some attention will be given to the accomplishments and prospects of the survey method. Specific instances in which existing forms of coverage have been improved and made more adequate will first be discussed. Methods of improvement through the survey approach will then be considered. Finally, attention will be directed to further needed improvements, together with an appraisal of the prospects for their accomplishment.

\section{III}

\section{Standardization of Policies and Endorsements}

One of the important steps in the improvement of insurance coverage from the standpoint of the public has been the standardization of policies and of the clauses and forms endorsed thereon. Undertaken early in the fire insurance field, the process spread until at the present time some measure of standardization exists in every major division of property insurance. For purposes of illustration and analysis, attention will be confined to fire insurance, automobile insurance, and inland marine insurance. 


\section{A. Fire Insurance}

As companies expanded their operations in the early days of insurance and began to rely on agents to administer the business rather than drafting each contract in the home office of the company, a degree of standardization became necessary for the protection of the company itself. But in addition, as the practice grew up of buying insurance on the same property from several companies, the confusion resulting from conflicting or contradictory clauses led to endless controversy and litigation. And, too, unique or obscure clauses in particular contracts often worked a hardship on a public unskilled in reading such documents and interpreting their effect. ${ }^{8}$ Action initiated by the New York Board of Underwriters was followed by more positive steps taken by the New York state legislature, which, in 1885, adopted a bill requiring a uniform policy for use in the state. ${ }^{9}$ The policy thus adopted was put into effect in 1886; its use spread to other states and ultimately it was adopted by 28 of the 48 states. $^{10}$ A revision of this form, adopted in New York in 1918, was adopted by most of the others with the exception of those following the Massachusetts form, adopted in 1873 and subsequently revised. In 1943, however, New York State adopted a still further revised form, and this one, with only minor variations in some cases, has been adopted in all of the states except Massachusetts, Minnesota, and New Hampshire, which still use the Massachusetts or New England form. ${ }^{11}$ Although not quite so complete, a parallel standardization has taken place with respect to the endorsements used in connection with the standard policy.

The important bearing of this development in fire insurance, as well as in other fields, upon the adequacy of the coverage afforded the public, warrants some attention. The use of standard wording serves, first of all, to promote an understanding of the effect of the contract. Those provisions whose meaning is doubtful are gradually clarified by practice and, where necessary, by court interpretation. Such understanding, once established, applies regardless of company, state (with slight variation), property, or the particular individuals or firms concerned. Thus, much of the mystery with which insurance seems to be shrouded in the public mind tends to disappear. With the disappearance of mystery, there tends to come the confidence so necessary if insurance is to provide the peace of mind which is one of its greatest services. Also, with standardization, the writing of policies concurrently ${ }^{12}$ becomes relatively simple, and the loss settlement procedure is simplified, thus eliminating controversy, delay, and loss and disappointment to the public.

As the preceding discussion suggests, fire insurance comes first to mind when we

${ }^{8}$ Robert Riegel and Jerome S. Miller, Insurance, Principles and Practices 362.

- John H. Magee, Property Insurance (rev. ed. r948).

${ }^{20}$ Julian Lucas, Standard Fire Insurance Policy of the State of New York, 19433 (1947).

11 The latter two states have minor statutory variations. See J. Edward Hedges, Practical Firz and Casuatty Insurance 63-64 (3d ed. 1948).

12 Policies are said to be "concurrent" when they contain the same designation of insured, designation of interest, description of property, and the same clauses, the wording of which is identical or of the same effect. 
seek specific examples of improvement in coverage resulting from standardization. But because recent steps taken in this field seem to fall more appropriately under "modernization and simplification," further discussion of standardization in fire insurance will be reserved for the next section where these forms of improvement are considered.

\section{B. Automobile Insurance}

Automobile insurance, a form which affects the public most widely, has in recent years attained a considerable measure of standardization. While numerous types of business concerns face hazards connected with the ownership, operation, maintenance, and repair of motor vehicles, consideration will be given here only to those hazards which may be insured under the combination material damage and liability policy, and to the use of this policy in covering such hazards. All or a substantial part of the standard policy may be applied to the hazards of loss or damage to the automobile itself and to bodily injury and property damage liability resulting from its ownership or use, as they affect those classifications of cars and trucks which include the vast majority of vehicles in use today. The discussion here will exclude such forms of insurance relating to the automobile as garage keepers' legal liability for damage to the autos of others, garage liability, long-haul truck liability to the public and to shippers of goods, material damage to dealers' cars, etc., all of which involve special problems, although a considerable degree of standardization exists in these fields.

It should be noted in passing that the combination automobile policy represents an outstanding example of a practical solution to the problem of mono-line restrictions. The public tends to think, as is natural, in terms of the risks surrounding the ownership and operation of an automobile, as a unit, not in terms of separate hazards of damage to the automobile (with the exception of collision, the exclusive province of fire insurance companies), and liability for damage by the automobile (the field reserved to casualty carriers, along with collision damage to the car itself, to which both are admitted). The solution represented by the combination policy is to issue, in effect, two separate policies printed on a single piece of paper, naming two companies as insurer, each assuming the hazards permitted it under the applicable insurance laws. The companies in such cases, of course, are affiliated, in many instances occupying the same home office quarters and having the same officers. So effective has this device proved that the public is frequently unaware that it is insured by two companies rather than by one.

Since the combination automobile policy really consists of two policies, standardization presented some problems. Obviously, steps were necessary, by the casualty companies independently, to standardize the liability portions of the policy, and by the fire companies independently, to standardize the material damage portions. Actually, the first step was taken by the casualty companies, the National Bureau of Casualty Underwriters and the American Mutual Alliance approving standard provisions in 
I936. ${ }^{13}$ Later, the National Automobile Underwriters Association and the American Mutual Alliance approved standard provisions for material damage insurance. ${ }^{14}$ While provisions have thus been standardized ${ }^{15}$ it should be noted that their use has never been required of bureau members nor made mandatory by law. Professor Kulp, however, reports an estimate, as of some years ago, that between 70 and 75 per cent of total automobile liability insurance was written on the standard forms. ${ }^{10}$

What have been the benefits of standardization of automobile insurance? Certainly they differ in part from those ascribed to standardization of the fire policy. The problem of concurrency which is so important in fire insurance is of little consequence here. The practice of multiple policies on the same risk is almost, if not totally, absent. Problems do arise, of course, when different interests-and different policies-become involved in the same loss. For example, liability may arise as a result of injury to a third party by a customer's automobile driven by the employee of a garage or repair shop. Standard provisions of the private passenger coverage clearly exclude liability of the operator of the garage. Such liability falls within the scope of the garage liability policy. But failure to coordinate the two formsand to standardize them-might result in either uninsured liability or over-lapping coverage, the latter perhaps lending itself to controversy as to which carrier is liable. Similar situations might arise where policies written on two or more private passenger cars were involved, were it not for the use of standard provisions.

Perhaps the most important benefit of standardization in the automobile insurance field is the promotion of public information regarding the coverage afforded. This problem is difficult enough when policies remain the same, but with variations from year to year and wide differences in forms used by the various companies, it becomes hopeless. The degree of standardization that has existed for some years now, and the comparative absence of radical change in standard provisions from year to year has made a significant contribution to improved public understanding of the forms of coverage available and the protection represented by each. Much yet remains to be accomplished, but this is another problem. When an automobile owner believes that because he has bodily injury liability insurance his company should pay him for wages lost as a result of an automobile accident involving only himself-as still happens occasionally-then public information regarding automobile insurance is obviously still deficient!

Our portrayal of the situation would be out of balance if we failed to recall that standardization also occasionally retards innovation and needed change. Without necessarily suggesting that the change involved was particularly desirable, I shall cite one example of hesitation to embrace innovation. It is the 80 per cent collision form, sometimes called the 80-20 form. Under this form the company agrees to pay 80

${ }^{13}$ C. A. Kulp, Casualty Insurance 166 (rev. ed. 1942).

14 HeDGes, op. cit. supra note II, at $186-187$.

${ }^{15}$ A specimen copy of the combination policy which includes the standard provisions is reproduced, id. at 294-303.

${ }^{10} \mathrm{KuLP}$, op. cit. supra note 13 , at 166 . 
per cent of any collision loss up to $\$ 250$. For any loss over this amount, the company pays the entire excess over $\$ 250$. It is in fact, then a 20 per cent deductible form, with a maximum deductible of $\$ 50$. The significant point is that it was introduced by companies outside the dominant stock company bureau, which declined to authorize the form for its members until the demands of agents who found the public insisting upon it, eventually forced adoption of the form. It is now written in nearly all states. While this case illustrates the static tendencies which come into being when standardization of forms becomes widespread, it also illustrates the way in which legitimate desires of the public eventually are met, in spite of the inevitable inertias within the industry.

\section{Inland Marine Insurance}

A word about marine insurance may be in order at this point, not because of the high degree of standardization attained, but because certain pressures within the industry may serve to disturb the standardization thus far accomplished.

Although most ocean marine policies in use today are based largely on the Lloyds policy of 1779 , it may properly be said that there is no universal standard policy in this field. ${ }^{17}$ Such standardization would require international agreement, something well-nigh impossible in a field as internationally competitive as ocean marine insurance. Inland marine insurance, so-called, as it operates in this country today, does not depend upon any such widespread agreement for the standardization of its forms. As one of the newer branches striving to attain significant premium volume in this country, it faced the problem of developing its sphere of operation in competition, at many points, for areas of risk already preempted by existing fire or casualty coverages. After a long period marked by conflict and even chaos, the agreed sphere of the entire marine branch of the business was marked out by the "Nationwide Definition of the Insuring Powers of Transportation and/or Marine Insurers."18 Of the classes of risks enumerated in this "definition," all involve some element of transportation. Those falling within the peculiar scope of inland marine insurance are, in addition to bridges and tunnels, ( $\mathrm{r}$ ) domestic transportation risks, and (2) personal property floater risks.

Under the terms of the Nation-wide Definition, the coverages offered by inland marine carriers have been stabilized, if not standardized. And so far as the rail, express, motor truck, and other transit forms are concerned, no new disturbance seems imminent. But the extension of fire and casualty policies under the new multiple-line privileges, so as to include hazards previously denied such carriers, may mean three-way competition for insurance of virtually the "all-risk" type on certain classes of personal property. Dwelling contents, clothing, personal effects, jewelry, furs, and the like are examples. As a result, a whole new problem of standardization may appear, finally being resolved only when a single standard form is devised to

\footnotetext{
${ }^{17}$ MAGEE, op. cit. supra note 9 , at 377 .

${ }^{18}$ The "Definition" is reproduced in HedGes, op. cit. supra note $\mathrm{r} \mathrm{r}$, at 322-325.
} 
cover the principal risks confronting the owners of such property, with no distinction as to the type of carrier privileged to write it.

\section{IV}

\section{Modernization and Simplification of Policies and Forms}

Certainty of interpretation, mentioned in the previous section as a benefit to both the carrier and the public, has frequently had a retarding influence upon needed revision of policies and forms. Sometimes, too, the difficulty of securing agreement among carriers, bureaus, and supervisory officials has had a similar effect. Nevertheless, substantial progress has been made. Many illustrations could be cited of modernization and simplification of policies, and of the endorsements designed for use with these policies to adapt them for the insurance of particular risks. Attention here will be confined to the outstanding example-the standard fire policy-and the dwelling and contents form, by means of which the fire policy is applied to the insurance of dwellings and personal property contained therein. ${ }^{\mathbf{1 9}}$

The standard fire policy first introduced in New York in 1886, as mentioned above, was subsequently adopted by 28 states, many of which continued to use this policy, or even adopted it, after the rgI8 revision in New York. Other states followed New York in adopting the I9I8 revision. Thus, except for variations in a few states, the fire policies in use at the time of the latest New York revision in 1943 had been drafted to fit conditions from twenty-five to nearly sixty years earlier. The situation was in part remedied by the awkward device of embodying in the various forms attached to the policy, standard waivers or permits setting aside the provisions which the insurer wished not to apply. Some examples may be cited, together with the nature and effects of the revisions embodied in the 1943 version of the policy now almost universally used.

Neither the 1886 nor the 1918 policy applied to loss occasioned by lightning, as such. Fire resulting from lightning was covered, but in many cases actual damage was confined to that caused by lightning itself and consequently was excluded by the policy. The impropriety of excluding such losses led to specific assumption of the lightning hazard under terms of the uniform dwelling and contents and other forms used in the various jurisdictions. With the adoption of the r 943 revision, the hazard was included in the coverage by specific assumption in the policy, making unnecessary its inclusion in the form attached.

In the 1886 policy a long list of specified conditions or situations "unless otherwise

${ }^{28}$ In many forms of insurance it is necessary to attach one or more endorsements in order to fit the contract to the particular risk to which it is to apply, and to limit or extend the coverage as may be agreed. In fire insurance various clauses have been developed for this purpose. Because of more or less standard practice with respect to the clauses used in insuring certain types of property, it has been possible to combine a number of clauses into what is called a "form." Forms have thus been devised fer a variety of types of risk, such as commercial buildings and their contents, apartment buildings, garages, manufacturing establishments, and the like. The form considered here is the one designed for applying the standard fire policy to the insurance of private dwellings and their contents. A copy of this form appears in HeDGes, op. cit. supra note 11 , at 29x-293. 
provided by agreement in writing added hereto," rendered the entire contract void. In the IgI8 version, these conditions were regrouped, certain of them having the effect of voiding the coverage if they existed or occurred, the others simply suspending coverage during their existence. ${ }^{20}$ The first group included ( $\mathrm{I}$ ) interest of the insured other than unconditional and sole ownership, (2) building on ground not owned by the insured in fee simple, (3) commencement of foreclosure proceedings with knowledge of the insured, (4) change in title or possession other than by death of insured (except change of occupants without increase of hazard), and (5) assignment of the policy before a loss. The second group, those having the effect of suspending the insurance, were (I) other insurance on the property; (2) increase in hazard by any means within the control or knowledge of the insured; (3) employment of mechanics in building, altering or repairing the described premises beyond a period of fifteen days; (4) generation of illuminating gas or vapor on the premises (any usage or custom to the contrary notwithstanding), keeping or using on the premises fireworks, Greek fire, phosphorus, explosives, benzine, gasoline, naphtha, gunpowder exceeding twenty-five pounds, or kersosene exceeding five barrels; (6) operation between ten p.m. and five a.m. or suspension of operation beyond ten days, if a manufacturing establishment; and (7) vacancy or unoccupancy beyond ten days. Also, unless otherwise agreed in writing, the company assumed no liability for loss or damage to any property while encumbered by a chattel mortgage.

By the time of the latest revision of the standard policy, it had become customary, under the terms of the uniform forms attached to the policy, to waive the application of nearly all of the above exclusions. Some were obviously obsolete and no longer needed. Those having to do with the interest of the insured were customarily satisfied by the regular practice of stating the interest of the insured in the policy designation, or by endorsement in connection with the transactions involving a change in interest or title. As to other insurance, the possibility of multiple recovery of a loss had become most remote, because of the information ordinarily developed during the adjustment process. Apparently the other "moral hazard" exclusions were, for the most part, not regarded as sufficiently serious to warrant retaining them.

The revision of the standard policy in 1943, following the practice already established, removed the bulk of the restrictions enumerated above, by simply omitting them from the policy. ${ }^{21}$ The only one retained in its original form was the one excluding liability "while the hazard is increased by any means within the control or knowledge of the insured." The period of permitted vacancy or unoccupancy was extended to sixty days (the form as used in most jurisdictions had previously permitted six months). As to other insurance, the r943 policy provides that "Other insurance may be prohibited or the amount of insurance may be limited by endorsement attached hereto."

\footnotetext{
${ }^{30} \mathrm{~A}$ copy of the $\mathrm{x} 9 \mathrm{x} 8 \mathrm{New}$ York Standard Fire Policy appears in S. S. Huebner, Property Insurance $34-39$ (1938).

${ }^{31}$ A copy of the 1943 New York Standard Fire Policy appears in HedGes, op. cit. supra note II, at 285-288.
} 
Another clause causing difficulty in early policies was the so-called "fallen building clause" which, in the I9I8 version, read: "If a building, or any material part thereof, fall except as the result of fire, all insurance by this policy on such building or its contents shall immediately cease." Thus, a relatively small loss due, say, to windstorm, preceding a fire, would result in voidance of the fire policy and leave the fire loss uninsured. But a problem of even more serious importance was created by the pro rata liability clauses incorporated in endorsements extending the fire policy to include hazards such as windstorm or earthquake. Where a policy covering both fire and windstorm was in effect, such policy would ordinarily waive the fallen building clause, the fire coverage in that particular policy picking up where the windstorm coverage stopped. Under the terms of the pro rata liability clause, however, the company assumed liability only pro rata with other fire insurance on the property, "whether valid or not." Thus, if there was other fire insurance on the property, the effect would be not only to limit recovery for the windstorm loss, but also for the fire loss. The insurance on fire alone would be void because of the fallen building clause, and insurance on fire and windstorm would bear only its pro rata share of the fire loss. Today, existing pro rata liability clauses still have the effect of limiting recovery for losses due to additional hazards under policies covering fire but extended to include such other hazards, when other fire insurance exists on the property. And such limitation is appropriate. But the special problems due to the fallen building clause no longer exist. They have been solved by the complete elimination of the clause from today's policies. If only rubble remains to be burned, any loss due to fire is covered.

One clause added to the fire policy has resulted in a simplification. Prior to adoption of the revised version, it was customary, in the form attached to the policy, to include destruction by order of civil authority "at the time of and for the purpose of preventing the spread of fire, provided that such fire did not originate from any of the perils excluded by this policy." Losses of this kind, although perhaps not "direct" loss by fire in a strict sense, ought properly to be covered by the fire policy. This has been accomplished by the inclusion in the policy itself, of wording similar to that above.

\section{$\mathrm{V}$}

\section{Liberalization of Contracts}

The extension of benefits afforded by existing contracts in recent years has had the effect of making a number of coverages much more inclusive and broadly more liberal, without, however, placing these contracts in the "all-risk" or "comprehensive" category. A few examples must suffice to illustrate this development.

\section{A. Fire Insurance}

Several cases in point may be drawn from fire insurance, referring specifically to the dwelling and contents form. One clause broadening the coverage reads as follows: 
The Insured may apply up to ten per cent (10\%) of the amount specified for Item I to cover private structures appertaining to the above described premises and located thereon, BUT NOT STRUCTURES USED FOR MERCANTILE, MANUFACTURING OR FARMING PURPOSES.

The value of the additional benefit is obvious. Without specifically describing or insuring an outbuilding, such as a detached garage, a portion of the insurance on the residence may be applied to it in case of loss. It should be noted, however, that this extension does not increase the total insurance, the specified amount of building insurance being the company's maximum liability for loss or damage to all property covered.

Another clause provides:

The Insured may apply up to ten per cent (ro\%) of the amount specified for Item I to cover rental value of the above described building or private structures, BUT NOT EXCEEDING ONE-TWELFTH (r/r2th) OF SAID TEN PER CENT (10\%) FOR EACH MONTH OF UNTENANTABILITY.

Thus, if a partial loss renders the residence untenantable, remaining insurance, subject to the stated limits, may be used to cover the loss of use, the sum provided ordinarily going a long way toward covering the rental of temporary substitute quarters.

There are others. The automatic reinstatement clause provides that losses of $\$ 250$ or less shall be automatically reinstated, that is, shall not reduce the amount of insurance applicable to subsequent losses, as would occur in the absence of such a clause. The inherent explosion clause includes within the coverage of the fire policy, losses due to explosion in the insured building resulting from hazards inherent therein. Examples would include explosion of gases in the firebox of a furnace, explosion of a gas water heater, etc. Explosion of steam boilers, however, is not included. Also, specific inclusion of fire caused by riot, a relatively new extension of the fire coverage, is provided by the policy itself, not by the form attached.

Another extension of the fire coverage is significant because it tends to make the dwelling contents insurance more nearly comparable-and hence more competitivewith inland marine floater forms. It is the ro per cent off-premises extension of the contents insurance. The clause reads:

The Insured may apply up to ten per cent (10\%) of the amount specified for Item 2 to cover (a) household furniture, (b) personal effects usually carried by travelers for personal use or wear BUT EXCLUDING ANIMALS, BIRDS, PETS AND BOATS; while elsewhere than on the described premises BUT WITHIN THE LIMITS OF THAT PART OF CONTINENTAL NORTH AMERICA INCLUDED WITHIN THE UNITED STATES OF AMERICA, ALASKA, THE DOMINION OF CANADA AND NEWFOUNDLAND; all belonging to the Insured or for which the Insured may be liable by law or may have prior to any loss assumed liability; or, at the sole option of the named Insured, belonging to a member of the family of and residing with the Insured; or which is being purchased under an installment plan, including any unpaid balance. Among other aspects of this clause it is noteworthy that, in contrast to the earlier 
exclusion of goods incumbered by a chattel mortgage, articles being purchased under an installment plan are now specifically covered.

\section{B. Automobile Insurance}

With respect to automobile insurance, other instances of broadened coverage may be cited. The development of "drive-other-cars" coverage offers a good example. This form of coverage, now accepted as a matter of course, started first as an endorsement for which an extra charge was made. Purchase of the endorsement extended the liability insurance of the insured to apply to him when he operated automobiles owned by others. The next step was to incorporate this additional coverage in the policy itself and to extend it to include the spouse of the named insured. A final step was to apply the liability coverage to "any other person or organization legally responsible for the use by such named insured or spouse of an automobile not owned or hired by such other person or organization." Thus, liability of the employer of the insured or spouse for property damage or personal injury arising out of the use not only of the insured's own automobile (which is covered under other provisions), but of any other automobile not owned or hired by the employer, is covered.

An early liberalization of the liability section of the automobile policy was its extension to apply to other drivers of the specified automobile, if driven with the permission of the insured. Recently it has been necessary because of bad experience to restrict this extension, particularly with respect to students or persons under a specified age. But the old exclusion formerly found in the policy itself, use by a person under the minimum age required for a driver's license or in any case under the age of $\mathrm{I}_{4}{ }^{22}$ has not been revived. Also, a former standard provision excluding liability when the automobile was driven in any competitive speed contest, while the automobile was rented or leased, or while used for demonstrating or testing, has been omitted from the present policy.

Within the past few months, one leading company has introduced a new and sweeping liberalization of its automobile policy. Effective immediately, and without additional cost, policies now in force (and presumably those subsequently to be issued by the company) provide the following added coverage: (I) liability for bodily injury and property damage arising from "occurrences"-not merely accidents; (2) newly acquired automobiles, for the remainder of the policy period; (3) trailers, regardless of type; (4) liability arising out of use by the named insured or spouse, of hired or rented automobiles, automobiles regularly furnished for their use, and a few others; and (5) some extensions of medical payments if included in the policy. - Numerous other examples might be cited to illustrate the tendency toward liberalization and modification to meet new conditions as they arise, but those noted should be adequate to indicate the responsiveness of the coverage offered to the changing needs of the public.

\footnotetext{
${ }^{22} \mathrm{KULP}$, op. cit. stupra note $\mathrm{I3}$, at $17 \mathrm{I}$.
} 


\section{Comprehensive aNd "All-Risk" Policies}

One of the most significant developments in recent years has been the introduction of certain policies providing broad coverage, written in such a way as to plug the gaps which previously had remained in some cases even after several policies had been purchased. Various terms have been used to designate such policies, including "comprehensive," "combination," "all-risk," and "schedule." While this paper is not excessively concerned with technical definitions, it may help to avoid confusion if the important distinctions surrounding each of these terms are pointed out.

The term "comprehensive" has been used to designate a variety of forms of coverage, with little uniformity as to the precise scope of coverage among the forms so designated. The liability forms conform most closely to the proper meaning of the term as suggested by Kulp-insurance against multiple hazards affecting the same risk, a person or business entity in the case of liability insurance. ${ }^{23}$ The comprehensive damage coverage in automobile insurance also conforms closely to this concept. While nothing is to be gained by quibbling over definitions, it would appear that nothing would be lost by using the term "comprehensive" to designate combination forms covering both liability and material damage, if written so as to be really inclusive of the major hazards involved.

The term "comprehensive" has sometimes been used to designate a broad or liberal form covering but a single hazard, but with relatively few exclusions. An alternative term, and one which is perhaps preferable, is "broad form," as for example, "broad form" theft. Actually, the latter term is ordinarily used to indicate a more liberal form than an earlier or perhaps a "standard" form of coverage. The term "schedule" applies ordinarily to a policy which may be written to include coverage of those hazards selected from a list or schedule. The schedule liability policy is an example. It may be more or less "comprehensive," depending upon the selections. It is distinguished from the more truly comprehensive forms, however, by the incorporation of a separate insuring clause to cover each hazard, rather than use of a single clause to cover all liability hazards of the insured except those specifically excluded.

All-risk forms require special mention. According to Kulp, the term really means all-hazard coverage on a particular risk. ${ }^{24}$ The term, in fact, is confined for the most part to inland marine insurance, applying to personal property floater forms. Such forms cover, typically, "all risks of loss or damage" to the described property, with the exception of certain enumerated causes of loss and types of property.

\section{A. Comprehensive Policies}

Space limitations preclude separate discussion of the benefits accruing to the public from use of each of the various so-called comprehensive forms. These fall
${ }^{33} \mathrm{Id}$. at 40.
"Id. at $4 \mathrm{r}$. 
primarily in the casualty field and include the "comprehensive general liability policy," the "comprehensive automobile liability policy" (the two combined forming the "comprehensive liability policy"), the "comprehensive personal liability policy," and the "comprehensive farmers liability policy," all covering liability, and the automobile "comprehensive" material damage coverage. The last three of those listed apply to individuals, primarily, rather than to business firms as do those first listed, and consequently hold wider general interest. For purposes of illustration, attention will be confined to the comprehensive personal (the comprehensive farmers liability policy being roughly parallel) and the automobile comprehensive material damage coverage.

The history of liability insurance helps to explain the way in which it has been written traditionally. As new hazards became apparent, new insuring clauses and new policies were devised to cover them. Thus, persons or business concerns faced with various liability hazards were forced to purchase a policy to cover each hazard for which insurance was desired. The schedule form had the effect of at least combining all coverages in a single document, but otherwise failed to improve the situation. Comprehensive policies went further, utilizing a single insuring clause and a single bodily injury liability limit for each accident.

The comprehensive personal liability insurance policy is basically a combination of residence liability and sports liability formerly written as separate policies, plus coverage for personal acts of the insured. The policy, standardized by agreement of the American Mutual Alliance and the National Bureau of Casualty Underwriters, was brought out in 1944 and revised in $19466^{25}$

The policy covers, automatically, all personal activities of the insured, other than business or professional, his or her spouse and members of the household, as well as liability due to ownership or occupation of the designated residence. The hazards covered consist of bodily injury liability, property damage liability, and employer's liability, all included in one insuring clause. There is a basic single limit of liability coverage of $\$ 10,000$ per occurrence, for one or more persons and for any or all of the three sources of liability.

The policy covers the cost of necessary medical care (independently of any liability) for members of the public or employees injured in any accident on the premises of the insured's residence, including a temporary residence, provided it is not owned by the insured. (A secondary residence owned by the insured requires the payment of additional premium.) The medical payments coverage also applies to vacant land (except farm land) owned by the insured. The liability coverage applies at the same additional locations as medical payments.

In addition to liability arising from business or personal pursuits, there are other exclusions. Liability imposed by any workmen's compensation law is excluded, as is liability to an employee if workmen's compensation insurance has been voluntarily provided for such an employee. The medical payments coverage excludes payment

\footnotetext{
${ }^{28}$ See Hedges, op. cit. stupra note $1 \mathrm{x}$, at 311-316.
} 
to any insured and to any regular resident of the premises or any person on the premises because of a business conducted there. Also excluded is liability arising out of ownership, maintenance, or use of motor vehicles and aircraft. There are also some limitations on liability from ownership or use of boats. Liability for damage to property used by, rented to, or in the care, custody, or control of the insured, is excluded.

Obviously, the coverage provided by the comprehensive personal liability policy includes most, if not all, of the liability hazards of the householder, as such. The exclusions, for the most part, are those to which the average person would not be subject or which ought, appropriately, to be otherwise insured. The resulting coverage is about as complete as could be expected consistently with maintaining rates which would not represent an undercharge in some cases and an overcharge in others. One gap in coverage requires further consideration, however. The workmen's compensation exclusion could have the effect of exposing the insured to loss where a person injured while making repairs, trimming trees, or the like, is held to come under the workmen's compensation law. This problem will be considered further under "needed improvements," below.

Automobile comprehensive material damage insurance seems to meet not only the requirements for the "comprehensive" designation as stated above, but also to come close to being an "all-risk" form. ${ }^{26}$ By its terms it covers "any direct and accidental loss of or damage to the automobile ... except loss caused by collision of the automobile with another object or by upset of the automobile or by collision of the automobile with a vehicle to which it is attached. Breakage of glass and loss caused by missiles, falling objects, fire, theft, explosion, earthquake, windstorm, hail, water, flood, vandalism, riot or civil commotion shall not be deemed loss caused by collision or upset." The exclusions are: ( $\mathrm{r}$ ) Loss while the automobile is used as a public or livery conveyance, unless this use is described and the proper premium paid; (2) Loss while the automobile is subject to any encumbrance not set forth in the policy; (3) war, invasion, civil war, etc.; (4) damage due to wear and tear, freezing, mechanical or electrical breakdown unless a result of other loss covered by the policy; (5) robes, wearing apparel or personal effects; and (6) tires, unless damaged by fire or stolen or unless the loss be "coincident" with other loss covered by the policy.

A few types of loss covered, in addition to those listed as not collision and consequently included, are malicious damage to paint or tires, damage to upholstery by vermin, and damage caused by attempted theft, to name a few. The coverage afforded is probably the broadest possible, consistent with equity in rates and a reasonable concept of hazards properly subject to insurance. Certainly it is sufficiently inclusive to meet any reasonable requirement.

\section{B. All-Risk Insurance}

The principal examples of all-risk insurance, so-called, are found in the inland marine field. Most forms are similar to the automobile comprehensive coverage dis-

${ }^{20}$ Sec specimen policy, id. at 295 . 
cussed above, applying only to loss or damage to the described property itself, not to liability for injury or damage to the persons or property of others, nor is medical payments coverage provided. A form of insurance providing the latter types of coverage in addition to direct loss is the combination residence policy, introduced a few years ago, and written in much the same way as the combination automobile policy. Aside from the combination automobile policy, this form seems to come closest to true "all-risk" or all-hazard coverage.

In addition to the inland marine "all-risk" forms, there are a few examples of coverage which is similar in scope, written by other than inland marine carriers. One is the "comprehensive dishonesty, disappearance and destruction" policy written by casualty companies. ${ }^{27}$ The coverage provided includes no less than eleven separate forms of insurance, some on an optional basis, among which are fidelity insurance, destruction, disappearance and wrongful abstraction of money and securities from inside or outside the premises or from safe deposit vaults; forgery, and mercantile open stock burglary and theft. Another casualty form is the residence and outside theft policy. The coverage provided approaches the all-risk category so far as direct loss is concerned, except for the exclusion of destruction, for example, by fire, explosion, or the like. No liability coverage, of course, is included.

Perhaps the form of coverage best illustrating "all-risk" insurance is the personal property floater, written by inland marine carriers. ${ }^{28}$ Since the policy applies to property in a permanent residence, as well as away from the premises or while in transit, it was originally prohibited in those states which subscribed to the Nationwide Definition, the provisions of which were outlined above. It has now been admitted in all states, however, by specific exception to the Definition in the states which have adopted it. The policy covers the insured and members of his family of the same household "world-wide, against all risks" to personal property, with a few exceptions. The principal types of property excluded are automobiles, aircraft and boats, animals, and unscheduled personal property pertaining to the business or profession of the insured. Excluded causes of loss are breakage of eye glasses, glassware, bric-a-brac, and similar fragile articles; mechanical breakdown; damage from dampness or extremes of temperature; wear and tear, moths, vermin, or inherent vice; and war. Coverage of money is restricted to $\$$ Ioo in any one loss, and of securities and other intangibles to $\$ 500$ in any one loss. These limits may be increased for additional premium.

The coverage provided by the personal property floater, obviously, is sufficiently broad to satisfy the personal and family needs of most insureds. The hazards and property excluded are those which ought properly to be covered by separate insurance, with payment of the appropriate rate. To include them in the coverage, increasing the rate proportionately, would be to discriminate against those not faced with the additional hazards, a danger always encountered in drawing up truly comprehensive forms.

${ }^{27}$ Id. at 223.

s" Id. at $147-148$. 


\section{The Insurance SuRvey}

What, specifically, is an insurance survey, and how may surveys help in improving property insurance coverage? In the earlier discussion it was indicated that a survey consisted of a careful listing of insurance needs, notation of existing insurance, and recommendation of needed adjustments or additional insurance. A more complete description will now be undertaken, followed by an analysis of the kinds of information revealed by a survey, the adjustments that may be called for, and the benefits derived by the insured. ${ }^{29}$

The first step in using the survey method, of course, is to secure the cooperation of the client. This is a part of the selling problem with which we are not here concerned. It is assumed, therefore, that the client has agreed to cooperate with the agent, and has supplied all the information requested. The first step, then, is to make a complete listing on forms available for the purpose, of all existing insurance covering the property, operations, and activities of the client. The forms used provide for the grouping of policies according to kind of coverage, with space for an analysis of policy provisions, endorsements, descriptions of property and interests therein, description of operations, rates, and other pertinent details.

The next step is to analyze the risks faced by the client. A form, which serves also as a check-sheet, may be used for the risk analysis. The necessary information will have been secured directly from the client, from his books and records where necessary, and, if desirable, from a physical inspection of his property and operations. From the descriptive information appearing on the risk analysis form, needed insurance coverage may be determined. With this may be compared the insurance already owned. If important hazards have been left uninsured, if there is underinsurance or overinsurance, if policies overlap, conflict, or are non-concurrent, necessary adjustments are recommended. Recommendations, with reasons, are usually presented separately.

A well executed survey seldom fails to produce information calling for some adjustment in the insurance coverage. Need for adjustment is not due, necessarily, to any fault in providing the original insurance. It may be due solely to changes in conditions. Frequently, however, it is due to the purchase of new insurance piecemeal, without proper regard to existing insurance. Some specific examples of conditions requiring changes in coverage are worth noting.

Property values change constantly, during some periods with great rapidity. Thus, property insured for the proper amount at one time may later be overinsured. If such is the case, the amount should be reduced and a premium saving effected. Or the property may be underinsured, resulting in the possibility of a greater loss than can be recovered or, perhaps worse, failure to comply with requirements of

\footnotetext{
${ }^{29}$ The subject of insurance surveys is treated comprehensively by Morrow and Lonergan in their monograph, Ralph E. Morrow, Insurance Surveys-Business and Personal (rev. ed., George E. Lonergan, I948). The writer has drawn upon this authoritative work in the discussion that follows.
} 
the coinsurance clause with a resulting penalty in case of partial losses. A similar situation would exist if buildings, equipment, or stock had been expanded without a proper increase in insurance.

Other changes may include changes in ownership, title, or interest in property which should be noted by endorsement on the policies affected. Certain operations may have been expanded or new ones started without proper adjustment in consequential loss, liability, or workmen's compensation insurance. Conversely, operations may have been discontinued without making needed changes in insurance. Or new employees may have been added, creating new fidelity risks which are not covered by existing bonds.

Even where there have been no fundamental changes such as those just mentioned, the survey frequently benefits the client by calling to his attention certain defects and pointing the way to their correction. The audit of policies includes a careful review of rates and premium computations to determine if they are correct. Occasionally errors are detected, the correction of which results in a saving. Or a saving in premiums may be possible by the use of a coinsurance clause. Loss prevention devices may have been installed entitling the insured to a rate reduction of which he is not aware. Or policy provisions may be unknowingly violated but permits may be available without charge to remove the violation. A vacancy or unoccupancy permit would be an example.

Then there is the matter of the most appropriate coverage for a particular hazard. Separate fire and windstorm policies may have been purchased when extended coverage could be provided for a similar cost and include insurance of additional hazards. Liability hazards may be insured under separate and uncoordinated policies, when a comprehensive form would give more adequate protection without additional cost. It may be desirable to replace a single risk burglary or robbery policy with a broader form or vice versa.

The benefits to the public from use of the survey method should be clear. It may not always be the case that recommended additional insurance will be wanted. But the client is made aware of the risk and his absence of coverage. On the other hand, more effective or economical methods of insuring particular risks are always to be desired, and often such methods can be determined only by a systematic survey. And in any case, adjustments to changing conditions require a periodic review of hazards as compared with insurance. Thus the insurance survey finds its place as one more means of improving coverage and assisting the industry to perform its function more effectively.

\section{VIII}

\section{Problems and Prospects of Nebded Improvengents}

Certain defects in coverage as now written have been noted in the previous pages-gaps difficult or impossible to fill, lack of proper coordination between 
existing policies affecting the same subject matter, the necessity of using awkward methods to provide needed coverage, and others. Attempts to improve the coverage available should be directed toward correcting all such defects. Thus, consideration might well be given to the inclusion of limited workmen's compensation coverage in the comprehensive personal liability policy, to provide for the case in which an unusual or unexpected interpretation of the law exposes the insured to workmen's compensation liability, as distinguished from common law liability for negligence. Such coverage might be made optional, or even subject to an audit of exposure to protect the company's premium income. Automatic extension of the medical payments coverage in the automobile policy might be provided to protect the minor children of the insured while riding in automobiles of others. Such insurance is needed to cover children participating in informal school transportation pools. Protection may be afforded, if at all, only by endorsement of the automobile policy.

An apparent gap in the coverage afforded by the extended coverage endorsement might well be given attention. The explosion insurance provided by the endorsement excludes loss due to explosion of a steam boiler "located in the building(s) described in this policy." Apparently, the tenant of an apartment, with fire and extended coverage insurance on his household goods, would not recover for loss caused by explosion of the boiler used to heat the building. Consideration might well be given to specific inclusion of such a loss under the circumstances cited. Otherwise, the only insurance of this hazard available would be a separate steam boiler policy written in the name of the tenant! Other similar situations have been suggested and need not again be cited here.

In the previous discussion some illustrations of the progress and benefits of standardization were noted. In the fire insurance field, adoption of a basic standard policy is almost universal. And the dwelling and contents form and extended coverage endorsement have been pretty generally standardized throughout the various jurisdictions. But much needs yet to be done. In a speech before the 1949 convention of the National Association of Insurance Agents in Chicago, Paul E. Keedy stressed the need for increased uniformity in the clauses in use in various jurisdictions. ${ }^{30}$ He mentioned specifically the coinsurance, consequential loss, reinstatement, and watchman clauses, among others, which require study and re-editing for uniformity and coordination with the standard fire policy. When this task has been completed, standardization of the numerous forms other than the dwelling and contents form may be undertaken.

But perhaps the most needed improvement in available insurance coverage, from the standpoint of the public, is a wider recognition of the principle on which the combination automobile policy is based-the tendency of the public to think in terms of the hazards surrounding particular types of property, as a unit. Automobile owners, for example, do not clearly distinguish between damage done to the auto-

${ }^{30}$ Keedy Seeks Uniformity, Eastern Underwriter, Sept. 23, 1949, p. 36. 
mobile and damage done $b y$ the automobile. "Automobile insurance," to the average insured, usually means insurance of both material damage and liability. Similarly, residence insurance, to be of the greatest value, should include the major hazards of both direct loss or damage and liability, including liability for the acts of members of the household. To this end, revival and extension of the combination residence policy would appear to be highly desirable.

The amendments to state insurance laws to permit multiple-line underwriting would seem to make such a development fully feasible. Already some steps have been taken in this direction. For example, a few fire insurance carriers in a few states have filed an endorsement to be attached to the extended coverage endorsement, adding the peril of theft to those covered by the policy. The insurance provided is somewhat more restrictive than the casualty residence and outside theft policy, both as to hazards and as to property covered. Moreover, the fire policy with extended coverage and residence theft, the casualty residence and outside theft policy, or even fire and extended coverage together with residence and outside theft insurance, fall somewhat short of the protection afforded by the personal property floater. None of these forms, except the fire policy, applies to the dwelling itself, and none, including the fire policy, provides any liability or medical payments coverage.

Some companies have attacked the problem of combination coverage on a somewhat broader basis. Widespread interest was aroused some months ago when one group within the industry announced its intention to introduce a new "all risks" insurance policy for dwellings and other types of buildings. ${ }^{31}$ The policy had been found acceptable under the laws of seventeen states and others were expected to approve it, in some cases after amendment to the insurance laws. ${ }^{32}$ Meanwhile, a Pennsylvania company introduced a new "packet" policy, approved under the multiple-line underwriting powers of that state. ${ }^{33}$ Basically, the policy, including optional coverages, combines automobile liability and material damage, personal liability, fire and extended coverage, and residence and outside theft. Apparently, however, coverage on the dwelling itself is excluded. Another company has been writing a similar policy for some time, the particular coverages included depending on rules of the state in which it is offered. In California, and perhaps other states, the coverage includes those hazards enumerated above, plus fire and extended coverage on the dwelling. Thus, individual companies, taking advantage of the newly granted multiple-line underwriting powers, are striking out into one important field.

In spite of the advances already made, however, realization of the maximum benefits of multiple-line underwriting must await the development of even more revolutionary methods. The policies introduced so far, merely combine, apparently,

al All Risks Policy for Dwellings, Rough Notes, July, 1949, p. 47.

${ }^{22}$ Development of an All Risks Dwelling Policy, Rough Notes, August, 1949, p. 9; Mutual Plan Progresses, Eastern Underwriter, August 5, I949, p. 20.

${ }^{3 s}$ Manufacturers Casualty New Packet Policy, Eastern Underwriter, Dec. 16, 1949, p. 27. 
coverages previously written separately. If gaps existed before, they probably still exist, even though the coverages are combined. But as experience with the combined coverage grows, any such gaps will undoubtedly be discovered and means found to fill them. The final step will be to devise a truly comprehensive form in which each separate coverage will be an integral part of the whole, fully coordinated with all the others.

\section{IX}

\section{ConcLusion}

In the preceding pages the forces at work to improve the property insurance coverage available to the public have been indicated, together with some description of how they operate. The improvements already accomplished are substantial. They have been illustrated and analyzed under the headings of standardization, modernization and simplification, liberalization, comprehensive and all-risk policies, and the insurance survey.

In spite of the accomplishments to date, many problems still lie ahead. Additional standardization and uniformity are needed. Even in the fire insurance field, where a standard policy is used almost universally, uniformity is still lacking in clauses and forms. Further simplification is desirable in nearly all fields. And realization of the full potentialities of comprehensive, combination, and all-risk policies undoubtedly lies ahead.

Under the latitude now permitted by multiple-line underwriting powers, individual companies are beginning to devise and to offer a truly comprehensive material damage and liability policy covering the residence, automobile, and personal activities of the individual and his family. But until this policy becomes a fully integrated whole rather than a series of separate policies bound together under a single cover, its development will not have been completed. Experience with the combination residence policy may serve to indicate how much further the combination principle should be carried. 